\title{
Erasmus mobilities and European identity- an exploratory incursion
}

\section{Cristina COJOCARU・}

\section{Abstract}

The Erasmus programme - EU`s flagship student exchange programme - has drawn more and more scholarly attention in the last decades, proportionally with its expansion. In this context, the link between an Erasmus experience abroad and European identity has also been explored by a series of studies. This paper aims to "zoom in" on this matter through a review of the literature that deals with this topic, touching also upon some of the relevant theories and policy documents for the study of this subject matter. To begin with, it will provide some clarifications about the concept(s) of (European) identity, putting them in the context of the Erasmus programme. Further on, it will engage in a mapping exercise of the some of the various approaches that have been taken, the case studies and the research methodologies that have been used or the results that have been observed in the dominant literature on this subject.

Keywords: Erasmus mobilities, Erasmus programme, student mobilities, European identity

\section{Introduction}

With a history of more than 30 years, the Erasmus programme is considered a "success story" of the European Union. It has facilitated the mobility of millions of students on the European continent and it has also extended (with the launch of the Erasmus+ programme in 2014) outside the European space. The European Commission (2019) estimates that 2 million more higher education students will benefit from the programme during the 2014-2020 timeframe and the programme is expected to have a substantial contribution at making mobility the "hallmark of the European Higher Education Area" (Bologna process, 2009).

Given its history and the number of beneficiaries that it involves, it comes as no surprise that many scholars took an interest in analyzing the impact that an Erasmus experience has on the participants. Thus, proportionally with the expansion of the programme from the last decade(s), this topic has started to receive more and more scholarly attention. Its impact has been approached in the literature from a variety of angles, ranging from the impact on language acquisition or on the so called "soft skills", to the impact on employability and so on.

\footnotetext{
•Ph.D. Candidate, West University of Timișoara, cristina.cojocaru@e-uvt.ro
} 
In this context, the present paper proposes a "zoom-in" on the causal relationship (if any) between Erasmus mobilities abroad and the premises for the crystallization or consolidation of a European identity. As one can presume from the title of this paper, it aims to be a theoretical exploration of the aforementioned matter.

Thus, the main purpose this study is to organize the literature dealing with the link between an Erasmus experience abroad and European identity. In this process, it also aims to pinpoint patterns and trends identified in the literature. Furthermore, its third objective is to emphasize some potential research gaps and make further recommendations for new research approaches that could enhance the scholarly knowledge on this topic.

For a better insight into the topic of interest, this study has a comprehensive structure, with the first section being focused on the concept of (European) identity, aiming for a clearer understanding of the term while also trying to identify some of its main characteristics that would be of use in the context of its association with Erasmus mobilities. As we shall see, this concept tends to elude clear-cut definitions, having a puzzling and heterogeneous nature.

Following this, the second section will introduce student mobilities, and more precisely the Erasmus programme, into the picture. Dwelling on the broader accepted perception than cross border mobility, and particularly student mobility, can foster European identity, a brief history of the programme will be sketched, followed by a discussion about whether the Erasmus programme was originally thought of as a programme that could have an influence in fostering a common European identity.

Finally, the third section will center around the segment of literature that has tackled directly the relationship between Erasmus mobilities and European identity in an attempt to have a better grasp on the various approaches that have been taken, the case studies and the research methodologies that have been used or the results that have been observed in the dominant literature on this subject.

\section{The concept of (European) identity}

For the purpose of the current paper, a "zoom in" on the concept of European identity seems necessary. Being a highly debated and often contested topic, it requires a careful "unpacking" and conceptualization, based on the selection of the literature related to this notion. Nonetheless, the vagueness of the concept, given by the multiple meanings that it has been attributed might still remain consistent.

It seems natural to start this discussion with noticing the fact that the debate about the mere existence or non existence of a European identity underlies the larger dispute between the essentialist view and the constructivist view. On the one hand, the first perspective refers to identities as "something that people are or have" (Ambrosi, 2013, p.145), as being comprised of a "fixed set of shared characteristics or experiences" (Moya \& Hames-García, 2000, p.231) that are inherent, eternal and unalterable (Jarach, 2004). On the other hand, the constructivist perspective is more flexible, referring to identities 
as being "fluid, relational, changing over time" (Ambrosi, 2013, p.145), being focused on their contingent, contested and constructed nature (Rumelili and Cebeci, 2016, p.32).

Not surprisingly, the literature on the subject of European identity dwells around the later perspective, approaching the process of identity construction from different views. As will be detailed in the further sections, the same applies in the discussion about the effect of an Erasmus mobility on the crystallization of a European identity.

Among the first noteworthy observations when talking about a European identity would be that (especially in relation to national/regional/local identity) it is not a matter of "either/or" and two or multiple forms of identification can coexist.

This idea would be in accordance with the what Henri Tajfel and John Turner`s social identity theory $(1978,1986)$ suggested, that a person does not just have a personal selfhood, but multiple selves and identities associated with the different groups that he/she is part of. In this context, social identity is "that part of an individual's self-concept which derives from his knowledge of his membership of a social group (or groups) together with the value and emotional significance to that membership" (1978, p.63). This emphasizes two important aspects of social identity, that are the acknowledgment of being part of a group, as well as the value that one puts on being part of the group. In the context of the formation of a European identity, a cross-border mobility might act as a trigger or as an enhancing factor for this feeling of belonging to a larger, European group, while contributing as well to giving more value and emotional significance to the idea of being part of this group (as shall be detailed in the further sections, the Erasmus experience is positively valued by the vast majority of participants).

Moreover, social identity theory suggests that social, economic or political processes could influence the formation of identity and the determination of behavior of the groups in their relations with each other, emphasizing once again the fluidity and the changing nature of the concept.

Thus, a person can feel at the same time "Catalan, Spanish and European", for example (Llera 1993, apud. Schlenker, 2007), with the local, national and supranational sense of belonging coexisting. Hence, European identity is not conceptualized under the form of a zero sum game, where an increase in feeling more European has to mean a decrease in the national and/or local loyalty (Schlenker, 2007, p. 32; Ambrosi, 2013, p.145).

In the constructivist approach the process of socialization is deemed to play an important role in the formation of identities. This element is noteworthy especially in the context of international student mobility, as socialization plays an important role during the exchange period (either with co-nationals, locals or other European/international peers), being a means of constructing, changing and/or renegotiating identity. Eder (2009) and Sigalas (2010), among others, have explored this aspect in their research, emphasizing the importance of social relations and socialization among the people living in Europe as an important factor in this process. Similarly, Checkel and Katzenstein (2009, apud Van Mol, 2013, p.210) indicate the influence of experience and social 
processes in this direction. Thus, enhanced cross-border interpersonal contact would be expected to be an effective method of developing a European identity.

If we would turn the question on a different side and ask ourselves who are the people more likely to develop a European identity, research on the topic (Fligstein, 2009) would point in the direction of citizens who speak foreign languages, are mobile, educated, young, professionals or white collar workers, people who travel (be it for study, work or leisure purposes). Intuitively, these would also be the categories more likely to interact and to be exposed to different aspects related to Europe and to European Union, to have interactions with other cross-national peers, to experience other cultures, to study or work in multicultural environments, to experience the instrumental benefits of being a EU(ropean) citizen and thus following the constructivist logic to crystallize or expand their affinity towards Europe.

Different authors would give different directions and understandings to the idea of a European identity, focusing on it either from a cultural perspective (Sassatelli, 2002), giving it a political or civic component (Checkel, 2009; Mitchell, 2012), having an instrumental approach with a focus on the benefits attributed to EU membership (Verhaegen et al.,2014), and so on. On the other hand, in terms of negative definition, some authors suggest to keep the focus on a broader understanding of European identity, one that does not necessarily identifies it with the European Union or with the European institutions (Van Mol, 2013, p.210), hence not restricting it to political interpretation, but rather focusing on its more extended social/cultural component(s).

This section might have brought more questions than answers, since, as previously mentioned the vagueness of the concept of European identity has been largely emphasized throughout the body of literature that has been consulted. However the purpose was not to cover the variety of facets that the concept implies which has been debated in the literature, but rather to try to bring to surface those aspects that would serve in the context of international student mobilities. As Brubaker and Cooper (2000) put it, identity- also applicable for European identity - can mean "too much" (if interpreted in a strong sense), "too little" (if interpreted in a weak sense) or even "nothing at all" (given its ambiguous nature).

As a first conclusion, it is important to emphasize the plurality of perspectives from which we can approach the concept of European identity. The constructivist approach is dominant in the literature. Subsequently, this form of identification is not a matter of "either/or" and two or multiple forms of identification can coexist. However, there is no unanimously accepted definition of the term, nor even a brief set of broadly acknowledged determinants or characteristics of European identity. Thus, future debates, discussions and research could focus more on these aspects, which could further on facilitate comparable results for studies on European identity.

\section{General considerations on the Erasmus programme}


When talking about student mobility in general, at a global level, in the literature it has been made a distinction between organized student mobility and spontaneous student mobility, with the first type of mobility being the most common on the European continent (Brooks and Waters, 2011, apud Van Mol, 2013). This is happening mainly as a result of the Erasmus programme (with its various subsequent names, during the different multiannual financial frameworks), which promotes organized mobilities and which has been institutionalized on a European policy level starting with its launch in 1987.

The programme takes its name from the Dutch philosopher Desiderius Erasmus, while being in the same time a backronym meaning EuRopean community Action Scheme for the Mobility of University Students. The programme was launched 1987, and while in the first year of implementation it enabled a number of 3244 students to pursue mobilities between 11 European states (Belgium, Denmark, Germany, Greece, France, Ireland, Italy, Netherlands, Portugal, Spain and United Kingdom), it now enables the mobility of more than 300000 participants every year, having become the EU flagship student exchange programme.

Thus, given the rather long history of the programme, and the fact that it is being implemented in the majority of higher education institutions of the 34 countries that are part of it - the programme is not restricted to the 28 EU Member States, it also includes Norway, Iceland, Liechtenstein, Turkey, Macedonia and Serbia as programme countriesand it has facilitated more than 4 million student mobilities during the last 30 years, Erasmus is considered as a "success story" of the European Union and is expected to grow even further. The European Commission (2019) estimates that during the 2014-2020 timeframe, 2 million more higher education students will benefit from the programme. It is also expected that it will bring an important contribution at reaching the target set within the Bologna process, that by $2020,20 \%$ of the graduates will have had a study or training period abroad (Bologna process, 2009). Moreover, it plays an important role in making mobility the "hallmark of the European Higher Education Area" (Bologna process, 2009).

By offering the students the opportunity to interact and to be exposed to a (more) different culture(s) for a period of one semester or one academic year, it is expected that they will get to know the culture of the host country and also discover and interact with other European cultures by the means of interaction and socialization with colleagues from various national backgrounds.

This rationale would go in the direction suggested by Fligstein (2008) who claimed that that increased interactions between Europeans can lead to a common European identity. Thus, he argues, as a result of direct interaction, "people will [...] come to see each other less as Italian and French, and thus foreign, and more and more as sharing common interests, a process that eventually will lead to seeing themselves more as Europeans and less as having merely a national identity" (Fligstein, 2008, p. 139). 
Thus, one of the rationales of the Erasmus programme would be to provide the context for students of different nationalities and cultural backgrounds to interact, to mingle, to identify common cultural elements between the home country, the host country, other countries and on a larger scale, even in Europe as a whole. As Sigalas (2010, p.246) put it, "even if this falls short of a fully fledged common culture, an increasing awareness of things that unite rather than divide Europeans is a step towards a common identity".

The characteristics of such an identity were not mentioned in the official documents that lead to the creation of the programme, back in 1987, except for some vague hints to a common European cultural heritage and a "People's Europe". As extracted from the Council of Minister's decision, the objectives of the Erasmus programme would be to:

"(i) achieve a significant increase in the number of students [...] spending an integrated period of study in another Member State, in order that the Community may draw upon an adequate pool of manpower with first hand experience of economic and social aspects of other Member States [...]

(iv) to strengthen the interaction between citizens in different Member States with a view to consolidating the concept of a People's Europe;

(v) to ensure the development of a pool of graduates with direct experience of intra-Community cooperation, thereby creating the basis upon which intensified cooperation in the economic and social sectors can develop at the Community level".

(Council of Ministers, 1987, pp. 21-22)

These targets would go in line with the Adonnino Report, "A people`s Europe", which stated that action at the Community level to encourage exchanges of young people between different Member States helps to promote the identity of Europe for young Europeans (Adonnino, 1985, p.25). The report also mentioned that the exchange scheme that was about to be put in place should have a "distinct European dimension", a "clear Community identity" (Adonnino, 1985, p. 26).

Nevertheless, the creation of a "People`s Europe" had a strategy based on symbols rather common for the national understanding of identity and culture, such as a flag, an anthem, as means of strengthening the image and identity of the Community, which proved to be an "euphemism for the dissemination of a common European identity and culture" (Shore, 2000 and Kraus, 2008, apud Sigalas, 2010, p. 243).

Even though clear mentions to a European identity are not explicitly put in the documents that laid the foundation of the mobility programme, as Petit (2007) showed, a closer look at the European Commission`s policy in the field of education will lead to the conclusion that through its actions it subsidiarily aims at redefining people`s "spatial representation of their community of belonging" or "the creation of shared values". In addition, Petit (2007) suggests that the decision to make education policy a common field of action from the early steps of the integration process can also be interpreted in the direction of actions taken with the outlook of fostering a shared common identity, 
necessary for the creation of an "ever closer union", as it was put from the preamble of the Rome Treaty establishing the European Economic Community.

Thus, despite the fact that it is not clearly framed among the core objectives of the programme, the impact of an international mobility abroad in shaping a European identity is an aspect of interest for the European Commission, as we can deduct also from the fact that the Erasmus Impact Studies that it conducted in 2014 and in 2019 had separate sections dedicated to this topic (European Commission, 2014; European Commission, 2019), the documents also stating that we can regard the programme as a tool that serves the purpose of promoting European identity among young people.

Needless to say, the Erasmus programmes serves multiple ends and in the literature we can find works focusing on its impact on the participants' employability, language skills, personal development and so on. However, we shall not insist on these approaches for the purpose of this paper, but focus on the literature that revolves around the causal relationship (if any) between an Erasmus mobility abroad and the premises for the crystallization or consolidation of a European identity, which shall be discussed in the next section.

\section{Erasmus and European identity - where does the literature stand?}

As a contribution to the European identity debates, there are a series of studies that are oriented towards cross-border mobility of people, and particularly student mobility, as a way of promoting and developing European identity and European integration. This section shall engage in a selective review of some of the dominant scholarly literature on this topic on the one hand, while also emphasizing some of the main theories relevant to the phenomenon being studied.

As is has been mentioned in the previous section, the purpose of contributing to a common, European identity has not been clearly put as a goal of the Erasmus programme. The programme would rather contribute to a kind of European integration from below. Offering the context for young European students to interact, to live together for a period of time (usually one semester or one academic year), to get to know each other and in extenso each other's background and culture could provide a good basis for selfsustainable integration process from below and for supporting the European project.

Thus, the general assumption from where we start would be that cross-border mobility in general and student mobility in particular can foster a European identity. This assumption would be in line with Gordon Allport`s (1954) "Contact Hypothesis" or "Intergroup Contact Theory" which claims that, under appropriate conditions, transnational and intergroup direct contact is one of the most effective mechanisms of identity-formation and of reducing intergroup bias.

Another useful tool in this direction is Karl W. Deutsch`s inter-national integration theory. His theory, based on ten historical cases of integration was focused on the conditions necessary for (political) integration to occur. Deutsch came to the conclusion that successful integration needed a "we feeling", a "sense of community" (Deutsch et al., 
2003, p.121) arguing that a common set of values, expanded communication and a large volume of international transactions sustained in time can lead towards the formation of an integrated community. Moreover, in terms of international transactions, people mobility would play an important role as it would create the framework for direct contact of people with different nationalities which could lead to creating the "we-feeling" and "sense of community" among them. Deutsch`s aforementioned ideas were followed later on by various scholars and applied in the context of the crystallization of a European "we feeling" and "sense of community" through cross-border mobility, particularly during an Erasmus mobility.

Sigalas (2010) tested the hypothesis that personal contact with other Europeans during the Erasmus mobility can promote a European identity. By the means of quantitative research, he applied a longitudinal survey to a number of Erasmus students (outgoing students from Great Britain, as well as incoming students to Great Britain) and also to a control sample of non-mobile students. His research, led to the (maybe surprising) conclusion that indeed the level of socialization with other European counterparts has increased, but this had only a slight impact on European identity. More than that, his research pointed out noticeable differences regarding this aspect between outgoing and incoming students. While outgoing students did show a modest increase in their European (self) identity, this situation was reversed in the case of incoming students, whose attachment to Europe slightly decreased following the mobility.

This latter find in Sigalas` work might come as a surprise, but we would treat it with caution and not generalize it to the entire Erasmus population. Rather, the fact that the aforementioned result came from a sample of incoming students in Great Britain, the most eurosceptic country (as more recent event have also showed), might provide a better explanation and also might give birth to a series of other questions. In this context, it would be useful to see if different patterns can be observed, depending on the country of origin and/or destination of students. This idea could be further explored in future research on this topic.

Some authors did go in the direction of including in their research sample students from different European countries. Christof Van Mol (2013) included in his sample students universities in Austria, Belgium, Italy, Norway and Poland in an attempt to test for regional variations related to developing a European identity through student mobility. By using a mixed approach, of both quantitative and qualitative methods, he reaches the conclusion that regional variations can be identified. Nonetheless, since his sample included four different categories of students (non mobile, potentially mobile, future mobile and mobile), the focus was on the differences between the four categories within each country, not only on mobile students and the differences between this category of students in the five countries. Van Mol brings into the attention the idea of a multiplicity of possible identifications with Europe, spotting a diversity of identification patterns and notices that in the case of mobile students, their identification with Europe becomes social as a result of personal experience (as opposed to non-mobile students, 
who show a merely political identification). His idea of an "experience-based social Europe" (Van Mol, 2013) that comes as a result of socialization, personal experience, international contacts is noteworthy and provides a good starting point for further research on this topic.

Nevertheless, the majority of studies on the selected topic tend to be focused on a sample from one country only, mainly due to the restrictive nature of the data gathering process. In their research, Russel King and Enric Ruiz-Gelices (2003) focus their attention on students from one university in Great Britain, with the purpose of identifying whether their year abroad influenced their European identity or consciousness and if they have a greater insight into European issues. Moreover, they also bring to front another aspect often related to a mobility experience- its influence on the future migration paths of participants. Thus, they focus on students as migrants, in trying to measure the participants` migration behavior after graduation.

Without being very clear how the sense of "feeling more European" is enhanced, it comes clear that social interaction has an important role. Thus, King and Ruiz-Gelices emphasize that mobility participants do show an increased levels of attachment to Europe, as a result of various (social) interaction. Also, they become more aware of belonging to a "European cultural space" and would identify themselves more as "partly european" or "european" than the students from the control group (who did not pursue a mobility). The study also emphasizes another relevant aspect- the participants increased attachment to the host country of their mobility, as a result of living there for a period of time, discovering its culture, history, people and socializing with local students (and not only). This could be interpreted as another step away from the national paradigm and towards the crystallization of a European affinity.

Moreover, the link between a mobility experience and further migration behavior that King and Ruiz-Gelices make is noteworthy, as they conclude that such an international experience often represents a first step towards various international, European and cross border activities (professional and personal) and foster further geographic moves.

Since it comes clear that the process of socialization plays an important part in the entire process of developing a "sense of community" and feeling more European, it might also be relevant to try to trace this process and the social interactions that take place during a mobility. In this context, the framework proposed by Bochner et al. (1977) comes in handy. They propose a framework consisting of 3 social networks for foreign students: a primary monocultural one consisting of close friendships with other conationals - this network provides the context for the expression of the culture of origin; a secondary, bicultural network, with host country nationals, which serves more instrumental purposes such as academic, administrative, logistical assistance, etc., and a third, international, network, a multicultural circle of friends (and acquaintances) with the function of offering company mainly in recreational contexts. 
Bochner's model can be validated in the case of Erasmus mobilities as well, as data collected by Sigalas (2010) and King and Ruiz-Gelices (2003) suggest the formation of the three networks and interaction paths that would revolve more around co-nationals for meaningful (both personal and academic) communication, around locals for instrumental issues and around European counterparts for less meaningful interaction.

In his work, Wilson (2011) brings also a new approach into the picture, in a panel study that looks not only at the relationship between an Erasmus mobility and (European) identity, but also at the political views and voting preferences of Erasmus students. With a sample consisting of mainly British (but also French and Swedish) students, he concludes that the attitudes towards Europe and the voting preferences of the "Erasmus generation" do not seem to diverge significantly from those of non-mobile students, adding to the literature on the limited/incremental impact of mobility in this direction.

In opposition to the aforementioned view, Mitchell (2012) brings empirical evidence supporting the civic nature of the Erasmus experience, based on self-reported assessments from Erasmus mobility participants of a rather large and heterogeneous (compared to other similar studies) sample. Thus, she shows that Erasmus students engage in meaningful cross-cultural interaction with other Europeans, become more interested in Europe and other Europeans as a result, and self-identity as European.

Another noteworthy aspect that has been pointed by various authors concerned about this topic (King and Ruiz-Gelices, 2003; Sigalas, 2010; Wilson, 2011; Van Mol, 2013) is the wider debate about the already "European nature" of students who choose to pursue a mobility. With little (if any) investigation on the potential "self selected" nature of mobility participants, some authors draw attention to the possibility that students who decide to benefit from an international mobility during their studies may be a priori already more oriented towards Europe. If this were the case, it would suggest that the transformative impact (if any) of the mobility period might actually be more reduced in real terms, given the students`already "European nature". Thus, while former Erasmus students may be more pro-European than their peers, this could be because students who choose to take part in it are already more pro-European.

This observation paves the way towards another recurrent element in the literature - the differences observed between mobile and non mobile students. Multiple studies (King and Ruiz-Gelices, 2003; Sigalas, 2010; Mitchell, 2012; Van Mol, 2013) engage in comparisons between the two different categories, finding consistent evidence that mobile students are more inclined to feeling more European and always score higher in the elements associated to an affinity towards Europe, while their non-mobile counterparts would show less attachment and a more reserved view.

As shown above, proportionally with the expansion of the Erasmus programme from the last decade(s), research questions started to emerge regarding the impact of such an experience in relation to various aspects, including the formulation/consolidation of a European identity. By looking at the literature dealing 
with this topic, we can notice that different authors have engaged in a plethora of approaches in their attempts to identify the relationship (if any) between Erasmus mobilities and European identity. Nonetheless,

\section{Final considerations}

The present paper aimed at engaging in an exploratory incursion in the literature revolving around the causal relationship between the formulation or consolidation of a European sense of identification of participants in an Erasmus mobility abroad, while touching also upon some of the relevant theories and policy documents for the study of this subject matter.

It was designed to have a comprehensive structure which debuts with some clarifications about the concept(s) of (European) identity and continues with further details about the European Commission`s Erasmus mobility programme, while also engaging in a preliminary analysis of the implications in the initial programme`s launch document on a common sense of identification among the Community`s citizens. It also tries to map the literature that deals with this topic and identify some of the dominant approaches that have been taken, the case studies and the research methodologies that have been used or the results that have been observed.

While the main limitation of the present paper is represented by the fact that it engages in a review that has a rather selective than systematic approach, its main contribution is that it creates the foundation for a comprehensive insight into the otherwise diverse literature dealing with Erasmus mobilities and European identity.

Besides bringing its contribution to organizing the literature dealing with the aforementioned topic, it also emphasizes some patterns and trends identified in the literature. Furthermore, it identifies some avenues for further research that could enhance the scholarly knowledge on this topic.

It is noticeable the fact that Eastern European countries are underrepresented in the literature. Thus it is recommended that further studies on this topic focus or include representative data from counties appertaining to this geographical region. Furthermore, the case of the Great Britain and Erasmus mobilities in the post-Brexit context should be further studied, adding to the existing literature indicating a decreased sense of European identification among British mobility participants. Another point for consideration and further discussions in future studies that was briefly touched upon is represented by the potential "self selected" nature of mobility participants, which could suggest that the transformative impact (if any) of the international mobility period might actually be more reduced in real terms. Last but not least, another dimension that deserves a closer look and should be included in further research projects is represented by the negative impact that an international mobility might have on mobility participants, as this element is broadly overlooked by the existing literature. 


\section{References}

Adonnino, P. (1985). A people's Europe: Reports from the ad hoc committee. Bulletin of the European Communities, Supplement no. 7/85.

Allport, G. (1954). The Nature of Prejudice, Cambridge, MA: Addison-Wesley.

Ambrosi, G. (2013). The Influence of the ERASMUS Programme on Strengthening a European Identity: Case Studies of Spanish and British Exchange Students in The ERASMUS Phenomenon - Symbol of a New European Generation?, eds: Feyen Benjamin / Krzaklewska, Ewa; Peter Lang Edition, 2013, 143-162.

Bochner, S., McLeod, BM., Lin, A. (1977). Friendship patterns of overseas students: a functional model. International Journal of Psychology 12, 277-294.

Bologna Process, Communiqué of the Conference of European Ministers Responsible for Higher Education, Leuven and Louvain-la-Neuve, 28-29 April 2009.

Brooks, R.,Waters, JL. (2011). Student Mobilities: Migration and the Internationalization of Higher Education. Palgrave Macmillan: Basingstoke.

Brubaker, R. and Cooper, F. (2000). Beyond "identity". Theory and Society, 29(1), 1-47.

Checkel J. T. and Katzenstein P. J. (2009), The politicization of European identities in Checkel J. T. \& Katzenstein P. J. (eds.). European identity. Cambridge: Cambridge University Press.

Council of Ministers. (1987). Council Decision of 15 June 1987 Adopting the European Community Action Scheme for the Mobility of University Students (ERASMUS). Official Journal of the European Communities 166, 20-24.

Commission of the European Communities. (1986). Proposal for a Council Decision Adopting the European Community Action Scheme for the Mobility of University Students (Erasmus). COM (85): 756/2 final.

Deutsch, K., Burrel, S.A., Kann, R.A., Lee, M.Jr., Lichterman, M., Lindgren, R.E.,Loewenheim, F.L., Van Wagenen, R.W. (2003). Political Community and the North Atlantic Area in The European Union: Readings on the Theory and Practice of European Integration, eds. Brent F. Nelsen and Alexander Stubb, 3rd edition. Boulder: Lynne Rienner, 121-143.

European Commission. (2014). The Erasmus Impact Study, Effects of mobility on the skills and employability of students and the internationalisation of higher education institutions, Luxembourg: Publications Office of the European Union.

European Commission. (2019). Erasmus+ Higher Education Impact Study, Luxembourg: Publications Office of the European Union.

European Commission. (2019). Erasmus+. What's in it for education, training, youth and sport?, available at https://ec.europa.eu/programmes/erasmusplus/sites/erasmusplus/files/erasmus-plus-at-a-glance en.pdf.

Eder, K. (2009). A Theory of Collective Identity. Making Sense of the Debate on a 'European Identity'. European Journal of Social Theory, 12(4), 427-447. 
Fligstein, N. (2008). Euro-Clash: The EU, European Identity, and the Future of Europe. Oxford: Oxford University Press.

Fligstein, N. (2009). Who Are the Europeans and How Does This Matter for Politics?. In J. T. Checkel \& P. J. Katzenstein (eds.). European identity. Cambridge: Cambridge University Press, 132-166.

Jarach, L. (2004). Essentialism and the Problem of Identity Politics, available at https://theanarchistlibrary.org/library/lawrence-jarach-essentialism-and-theproblem-of-identity-politics.lt.pdf.

King, R. Ruiz-Gelices, E. (2003). International student migration and the European 'year abroad': Effects on European identity and subsequent migration behaviour. International Journal of Population Geography 9(3), 229-252.

Mitchell, K. (2012). Student mobility and European identity: Erasmus study as a civic experience? Journal of Contemporary European Research, 8(4), 490-518.

Moya, P.M.L, Hames Garcia, M.R. (2010). Reclaiming Identity: Realist Theory and the Predicament of Postmodernism, University of California Press.

Petit, I. (2007). Mimicking history: The European Commission and its education policy. World Political Science Review 3(1), 1-24.

Rumelili, B. and Cebeci, M. (2016). Theorizing European Identity. Contributions to constructivist international relations debates on collective identity in European Idenity Revisited. New approaches and recent empirical evidence, eds: Kaina V., Karolewski I.P., Kuhn S., New York, Routledge, 31-43.

Sassatelli, M. (2002). Imagined Europe: The Shaping of a European Cultural Identity through EU Cultural Policy, European Journal of Social Theory, 5 (4), 435-451.

Schlenker, A. (2007). Multiple identities in Europe: A conceptual and Empirical Analysis. EU-CONSENT Workpackage V. Democracy, Legitimacy and Identities. Available online: http://www.eu-consent.net/library/PhD/Schlenker.pdf

Sigalas, E. (2010). Cross-border mobility and European identity: The effectiveness of intergroup contact during the Erasmus year abroad. European Union Politics 11 (2), 241265.

Tajfel, H. (1978). Differentiation between social groups: Studies in the Social Psychology of Intergroup Relations. London: Academic Press.

Tajfel, H. and Turner, J.C. (1986). The Social Identity Theory of Intergroup Behavior. In: Worchel, S. and Austin, W.G., Eds., Psychology of Intergroup Relation, Hall Publishers, Chicago, 7-24.

Van Mol, C. 2013. Intra-European Student Mobility and European Identity: A Successful Marriage? Population, Space and Place 19 (2), 209-222.

Verhaegen, S., Hooghe, M. and Quintelier, E. (2014). European Identity and Support for European Integration: A Matter of Perceived Economic Benefits? Kyklos, 67(2), 295-314. Wilson, I. (2011). What should we expect of 'Erasmus generations'? Journal of Common Market Studies, 49, 1113-1140. 